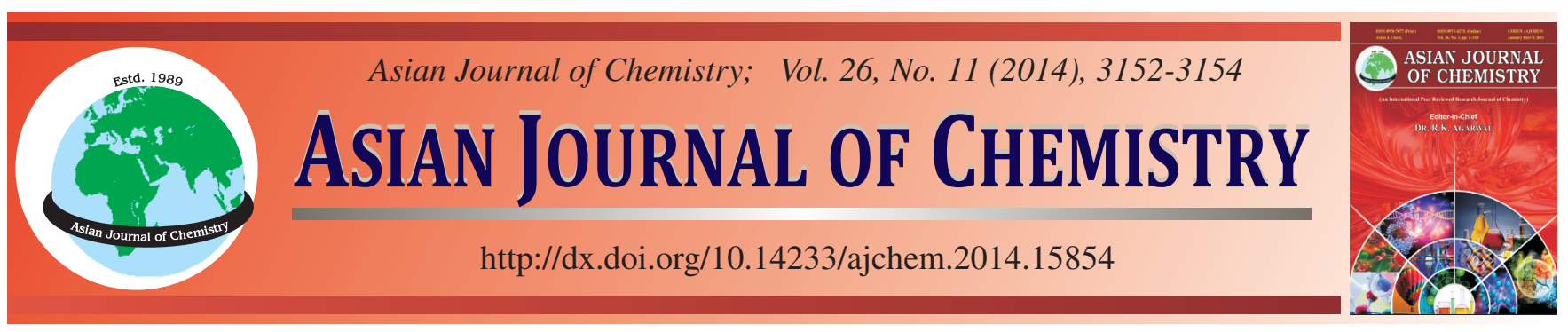

\title{
A New Dibenzocyclooctadiene Lignan from the Fruits of Schisandra lancifolia and Its Cytotoxicity
}

\author{
Hai-Ying Yang ${ }^{1}$, Guang-Jian Shen ${ }^{1}$, Yin-Ke Li $^{1,2}$, XIAn-Xue Wu $^{2}$, Gang Du ${ }^{1}$, Qiu-Fen Hu ${ }^{1}$ and Xue-Mei GaO ${ }^{1, *}$
}

${ }^{1}$ Key Laboratory of Chemistry in Ethnic Medicinal Resources, State Ethnic Affairs Commission \& Ministry of Education, Yunnan University of Nationalities, Kunming 650031 P.R. China

${ }^{2}$ College of Resource and Environment, Yuxi Normal University, Yuxi 653100 P.R. China

*Corresponding author: Fax: +86 871 5910017; Tel: +86 871 5910013; E-mail: gao_xuemei@ hotmail.com

Received: 1 June 2013;

Accepted: 1 August 2013;

Published online: 25 May 2014;

AJC-15203

A new dibenzocyclooctadiene lignan, lanciphenol B (1) was isolated from the fruits of Schisandra lancifolia. The structure of 1 was elucidated by spectroscopic methods including extensive $1 \mathrm{D}$ - and $2 \mathrm{D}-\mathrm{NMR}$ techniques. Compound $\mathbf{1}$ was evaluated for its cytotoxicity, and showed cytotoxicity against NB4 and MCF7 cell with $\mathrm{IC}_{50}$ values of 7.8 and $8.9 \mu \mathrm{M}$, respectively.

Keywords: Dibenzocyclooctadiene lignan, Schisandra lancifolia, Cytotoxicity.

\section{INTRODUCTION}

Plants of the genus Schisandra are used commonly in traditional Chinese medicine for their diverse beneficial bioactivities. The fruits of Schisandra plants are used as sedative and tonic agents ${ }^{1,2}$. Previous studies have shown that this genus is a rich sources of lignans and triperpenoids, especially the dibenzocyclooctadiene lignans, which have been found to possess some beneficial activities ${ }^{3-5}$.

Schisandra lancifolia belongs to the genus Schisandra of the family Schisandraceae. It is a climbing plant mainly distributed in Yunnan, Sichuan and Shanxi Provinces of China ${ }^{6}$. In previous studies, some new dibenzocyclooctadiene lignans were isolated from the fruits of S. lancifolia from of Erlang mountain area of Sichuan Province ${ }^{7}$. In our continuing efforts to identify bioactive natural products from the medicinal plants of the Schisandraceae, a chemical investigation on the fruits of S. lancifolia from Lijiang County, Yunnan Province was carried out. As a result, a new dibenzocyclooctadiene lignan (1) was separated from this plant and the cytotoxicity of $\mathbf{1}$ was evaluated. The structure elucidation and biological activities of 1 were also described.

\section{EXPERIMENTAL}

Optical rotations were measured in a Horiba SEPA-300 polarimeter. UV spectra were obtained on a Shimadzu UV2401A spectrophotometer and CD spectra were measured on a JASCO J-810 spectropolarimeter. A Tenor 27 spectrophotometer was used for scanning IR spectra ( $\mathrm{KBr}$ pellets). 1D- and 2D-NMR spectra were recorded on a DRX-500 spectrometer with TMS as internal standard. Chemical shifts $(\delta)$ are expressed in ppm with reference to TMS. HRESIMS was performed on an API QSTAR spectrometer or a VG Autospec3000 spectrometer. Preparative HPLC was performed on a Shimadzu LC-8A liquid chromatograph equipped with Zorbax PrepHT GF $(21.2 \mathrm{~mm} \times 25 \mathrm{~cm}, 7 \mathrm{~mm})$ column or Venusil MP C18 (20 mm $\times 25 \mathrm{~cm}, 5 \mathrm{~mm})$ column. Column chromatography was performed using silica gel (200-300 mesh, Qing-dao Marine Chemical, Inc., Qingdao, People's Republic of China), Lichroprep RP-18 gel (40-63 $\mu \mathrm{m}$, Merck, Darmstadt, Germany), Sephadex LH-20 (Sigma-Aldrich Corp. -St Louis, USA), or MCI gel (75-150 $\mu \mathrm{m}$, Mitsubishi Chemical Corporation, Tokyo, Japan). Column fractions were monitored by TLC and the spots were visualized by heating the plates after spraying with $5 \% \mathrm{H}_{2} \mathrm{SO}_{4}$ in $\mathrm{EtOH}$.

The fruits of S. lancifolia were collected in Lijiang County of Yunnan Province, People's Republic of China, in September 2011. The identification of the plant material was verified by Prof. Xi-Wen Li of Kunming Institute of Botany, Chinese Academy of Sciences. A voucher specimen (KIB 11-9-58) has been deposited in our Laboratory.

Extraction and isolation: The air-dried and powdered fruits of $S$. lancifolia $(2.2 \mathrm{~kg})$ were extracted four times with $70 \%\left(\mathrm{CH}_{3}\right)_{2} \mathrm{CO}(4 \times 3 \mathrm{~L})$ at room temperature and filtered, with the filtrate evaporated under the reduced pressure and partitioned with EtOAc $(3 \times 1 \mathrm{~L})$. The EtOAc partition $(152 \mathrm{~g})$ was applied to silica gel (200-300 mesh) column chromatography, eluting with a $\mathrm{CHCl}_{3}-\left(\mathrm{CH}_{3}\right)_{2} \mathrm{CO}$ gradient system $(20: 1$, 
9:1, 8:2, 7:3, 6:4, 5:5), to give five fractions, A-E. Further separation of fraction $\mathrm{B}(18.6 \mathrm{~g})$ by silica gel column chromatography, eluted with chloroform-acetone (20:1-1:2), yielded mixtures of B1-B6. Fraction B2 (5.2 g) was subjected to silica gel column chromatography using petroleum ether-acetone and semi-preparative $\mathrm{HPLC}\left(65 \% \mathrm{MeOH}-\mathrm{H}_{2} \mathrm{O}\right.$, flow rate 12 $\mathrm{mL} / \mathrm{min}$ ) to give $\mathbf{1}(22.6 \mathrm{mg})$.

Lanciphenol B (1): White powder; $[\alpha]_{\mathrm{D}}^{24.8}+14.5$ (c 0.20, $\mathrm{MeOH}) ; \mathrm{CD}(\mathrm{c} 0.05, \mathrm{MeOH}) \lambda_{\max } \mathrm{nm}(\Delta \varepsilon) 250$ (-46.5), 236 (-30.2), 222 (+22.8), 215 (+35.3); IR (KBr, $\left.v_{\max }, \mathrm{cm}^{-1}\right) 3492$, 2965, 2930, 2828, 1730, 1605, 1490, 1462, 1410, 1385, 1248, 1192, 1127, 982, 932, 853; ${ }^{1} \mathrm{H}-$ and ${ }^{13} \mathrm{C}$ NMR data, Table-1; ESIMS (positive ion mode) $\mathrm{m} / z, 495[\mathrm{M}+\mathrm{Na}]^{+}$; HRESIMS (positive ion mode) $\mathrm{m} / \mathrm{z} 495.1998[\mathrm{M}+\mathrm{Na}]^{+}($calcd. 495.1995 for $\mathrm{C}_{26} \mathrm{H}_{32} \mathrm{NaO}_{8}$ ).

Cytotoxicity assay: The cytotoxicity tests for these compounds were performed against NB4 (human acute promyelocytic leukemia cells), A549 (Human lung adenocarcinoma epithelial cells), SHSY5Y (human neuroblastoma cells), PC3 (Human prostate cancer cell) and MCF7 (human breast adenocarcinoma cells) tumor cell lines by MTT-assay with paclitaxel as the positive control ${ }^{13}$. All experiments were performed in triplicate. The $\mathrm{IC}_{50}$ was defined as the concentration of the test compound resulting in a $50 \%$ reduction of absorbance compared with untreated cells.

\section{RESULTS AND DISCUSSION}

The fruits of S. lancifolia were extracted with $70 \%$ acetone. The extract produced was subjected repeatedly to column chromatography on silica gel, Sephadex LH-20, RP-18 and RP-HPLC, to afford the new dibenzocyclooctadiene lignan, lanciphenol B (1). Its structure was shown in Fig. 1 and its ${ }^{1} \mathrm{H}$ and ${ }^{13} \mathrm{C}-\mathrm{NMR}$ spectroscopic data were listed in Table-1.

Compound 1 was obtained as yellow gum and was assigned the molecular formula of $\mathrm{C}_{26} \mathrm{H}_{32} \mathrm{O}_{8}$, by HRESIMS at $m / z 495.1998[\mathrm{M}+\mathrm{Na}]^{+}$(calcd. $m / z$ 495.1995). The ${ }^{1} \mathrm{H}$ and ${ }^{13} \mathrm{C}$ NMR spectra data implied that 1 should be a dibenzocyclooctadiene lignan possessing three methoxy groups, a methylenedioxyl group and a phenolic hydroxy group on the aromatic ring ${ }^{7}$. The ${ }^{1} \mathrm{H}$ and ${ }^{13} \mathrm{C}$ NMR spectra of $\mathbf{1}$ were very similar to those of schilancifolignan $\mathrm{C}$ on the dibenzocyclooctadiene skeleton ${ }^{7}$. The difference resulted from the appearance of $O$-isobutyryl group and the lack of an acetoxyl

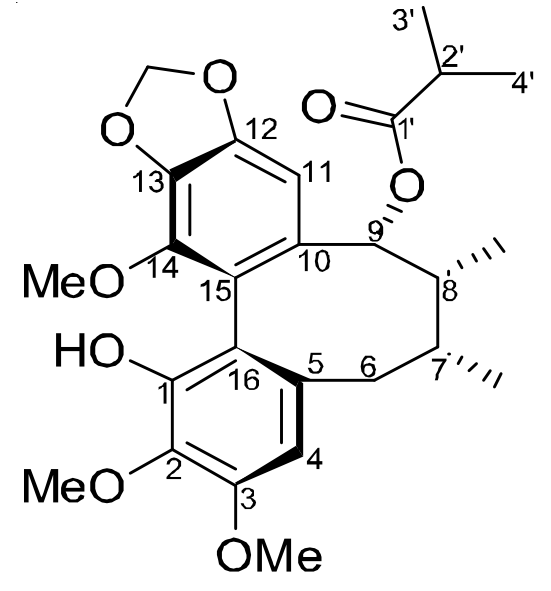

Fig. 1. Structure of lanciphenol B (1)

group in 1, which was supported by the absence of a acetoxyl group singal and appearance of a $O$-isobutyryl signal [176.0 s, $\left.35.2 \mathrm{~d}, 18.9 \mathrm{q}(2 \mathrm{C}) ; \delta_{\mathrm{H}} 2.45 \mathrm{~m} \mathrm{1H}, 0.91 \mathrm{~d} J=7.0(6 \mathrm{H})\right]$ when compared with schilancifolignan $\mathrm{C}$. Further analysis of the HMBC correlations (Fig. 2) showed that the $O$-isobutyryl group located at C-9, three methoxy groups located at C-2, C3 and $\mathrm{C}-14$, the methylenedioxyl group located C-12 and C13 and the phenolic hydroxy group occurred at $\mathrm{C}-3$, respectively. The configurations of the biphenyl groups in all isolated dibenzocyclooctadiene lignans in this investigation were determined based on their characteristic circular dichroism (CD) spectra. The CD spectra of S-biphenyl configured lignans show a positive Cotton effect at 215-225 nm and a negative Cotton effect at 240-260 nm. However, lignans with the R-biphenyl configuration show a negative Cotton effect at 215$230 \mathrm{~nm}$ and a positive Cotton effect at $240-260 \mathrm{~nm}^{8,9}$. The CD spectrum of 1 exhibited a negative Cotton effect at $250 \mathrm{~nm}$ and a positive Cotton effect at $222 \mathrm{~nm}$, indicating that $\mathbf{1}$ has an S-biphenyl configuration ${ }^{8,9}$. Moreover, the configuration of the $O$-isobutyryl group at C-9 can be determined to be $\alpha$-orientation by the ROESY correlations (Fig. 3) of H-11 with H-8 and $\mathrm{H}-9$. The other substituent positions and stereochemistry assignments of $\mathbf{1}$ were also determined by the comparison of the ROESY correlations and coupling by compared with the reported compounds ${ }^{7}$. Therefore, the structure of $\mathbf{1}$ was determined as shown and it has been given the trivial name of lanciphenol B.

\begin{tabular}{|c|c|c|c|c|c|}
\hline \multicolumn{6}{|c|}{$\begin{array}{c}\text { TABLE-1 } \\
\text { JMR DATA OF COMPOUND }\end{array}$} \\
\hline No. & $\delta_{\mathrm{C}}(\mathrm{m})$ & $\delta_{\mathrm{H}}(\mathrm{m}, J, \mathrm{~Hz})$ & No. & $\delta_{\mathrm{C}}(\mathrm{m})$ & $\delta_{\mathrm{H}}(\mathrm{m}, J, \mathrm{~Hz})$ \\
\hline 1 & $149.2 \mathrm{~s}$ & & 14 & $141.5 \mathrm{~s}$ & \\
\hline 2 & $138.5 \mathrm{~s}$ & & 15 & $121.5 \mathrm{~s}$ & \\
\hline 3 & $151.6 \mathrm{~s}$ & & 16 & $123.1 \mathrm{~s}$ & \\
\hline 4 & $112.7 \mathrm{~d}$ & $6.94, \mathrm{~s}$ & 17 & $15.8 \mathrm{q}$ & $0.98, \mathrm{~d}, J=7.6$ \\
\hline 5 & $134.6 \mathrm{~s}$ & & 18 & $20.6 \mathrm{q}$ & $1.15, \mathrm{~d}, J=7.6$ \\
\hline $6 \alpha$ & $38.7 \mathrm{t}$ & $2.68, \mathrm{~d}, J=11.6$ & $1^{\prime}$ & $176.0 \mathrm{~s}$ & \\
\hline $6 \beta$ & & $2.82, \mathrm{dd}, J=11.6,6$ & $2^{\prime}$ & $35.2 \mathrm{~d}$ & $2.45, \mathrm{~m}$ \\
\hline 7 & $36.2 \mathrm{~d}$ & $2.15, \mathrm{~m}$ & $3^{\prime}, 4^{\prime}$ & $18.9 \mathrm{q}$ & $0.91, \mathrm{~d}, J=7.0$ \\
\hline 8 & $39.5 \mathrm{~d}$ & $2.18, \mathrm{~m}$ & OMe-2 & $60.6 \mathrm{q}$ & $3.91, \mathrm{~s}$ \\
\hline $9 \alpha$ & $84.3 \mathrm{t}$ & $5.38, \mathrm{~d}, J=8.2$ & OMe-3 & $55.8 \mathrm{q}$ & $3.87, \mathrm{~s}$ \\
\hline 10 & $136.4 \mathrm{~s}$ & & OMe-14 & $61.1 \mathrm{q}$ & $3.82, \mathrm{~s}$ \\
\hline 11 & $106.2 \mathrm{~d}$ & $6.74, \mathrm{~s}$ & $-\mathrm{OCH}_{2} \mathrm{O}-$ & $101.5 \mathrm{t}$ & $5.82,5.87, \mathrm{~s}$ \\
\hline 12 & $148.2 \mathrm{~s}$ & & $\mathrm{Ar}-\mathrm{OH}$ & & 10.68, brs \\
\hline 13 & $136.8 \mathrm{~s}$ & & & & \\
\hline
\end{tabular}




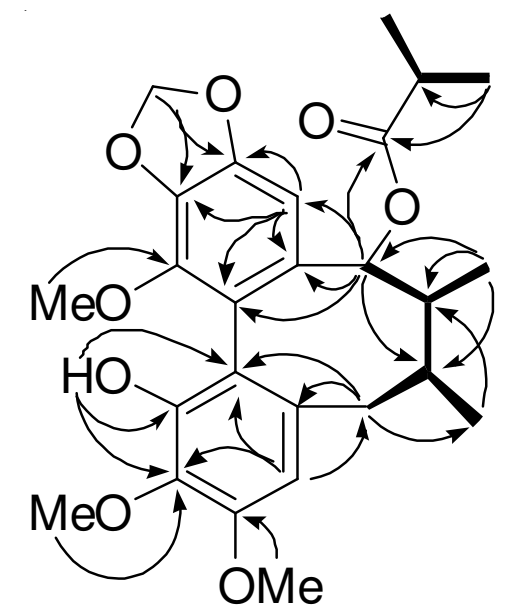

Fig. 2. Selected HMBC ( $-\mathbf{\Delta}$ ) and $1 \mathrm{H}-1 \mathrm{HCOSY}(\boldsymbol{-})$ correlations of $\mathbf{1}$

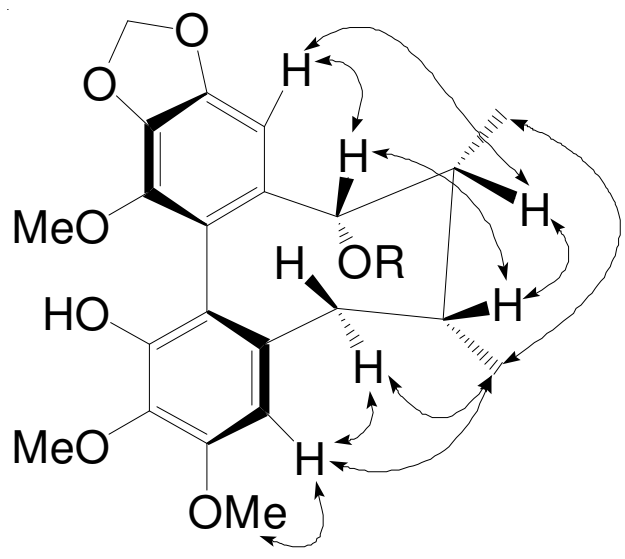

Fig. 3. Key ROESY ( $)$ ) correlations of $\mathbf{1}$

Since some dibenzocyclooctadiene lignans from Schisandra species are reported to possess cytotoxicity for cancer cell lines $^{7,10-12}$. Compound $\mathbf{1}$ was tested for its cytotoxicity against five human tumor cell lines (NB-4, A-549, SHSY5Y, PC-3 and MCF-7) using the MTT method as reported ${ }^{13}$.
The cytotoxicity tests for compounds were performed against NB-4, A-549, SHSY5Y, PC-3 and MCF-7 tumor cell lines by MTT-assay with paclitaxel as the positive control. The results shown that the compound $\mathbf{1}$ exhibited moderate cytotoxicity against NB-4 and MCF-7 cell with $\mathrm{IC}_{50}$ values of 7.8 and $8.9 \mu \mathrm{M}$, respectively.

\section{ACKNOWLEDGEMENTS}

This project was supported financially by the Excellent Scientific and Technological Team of Yunnan Higher Education (2010CI08) and the Yunnan University of Nationalities Green Chemistry and Functional Materials Research for Provincial Innovation Team (2011HC008).

\section{REFERENCES}

1. Committee of Pharmacopoeia of China, Pharmacopoeia of the People's Republic of China (Part 1), Pharmacopoeia Commission of the Ministry of Public Health of P.R. China, Beijing, P.R. China, pp. 454-455 (1990).

2. L.J. Xu, H.T. Liu, Y. Peng and P.G. Xiao, J. System. Evol., 46, 692 (2008).

3. J.B. Chang, J. Reiner and J.X. Xie, Chem. Rev., 105, 4581 (2005).

4. W.L. Xiao, R.T. Li, S.X. Huang, J.X. Pu and H.D. Sun, Nat. Prod. Rep., 25, 871 (2008).

5. X.G. Li, Q. Gao, W. Wen, P.F. Zhang, F. Xiao and H.M. Luo, J. Chin. Med. Mat., 28, 156 (2005).

6. Flora Yunnanica, Science Press, Beijing, Vol. 11, p. 22 (2000).

7. G.Y. Yang, P. Fan, R.R. Wang, J.L. Cao, W.L. Xiao, L.M. Yang, J.X. Pu, Y.T. Zheng and H.D. Sun, Chem. Pharm. Bull. (Tokyo), 58, 734 (2010).

8. Y. Ikeya, H. Taguchi, I. Yoshioka and H. Kobayashi, Chem. Pharm. Bull. (Tokyo), 27, 1383 (1979).

9. Y. Ikeya, E. Miki, M. Okada, H. Mitsuhashi and J.G. Chai, Chem. Pharm. Bull. (Tokyo), 38, 1408 (1990).

10. G.Y. Yang, R.R. Wang, Z.H. Gao, Y.K. Li, L.M. Yang, X.N. Li, S.Z. Shang, Y.T. Zheng, W.L. Xiao and H.D. Sun, Nat. Prod. Commun., 8, 467 (2013)

11. G.Y. Yang, R.R. Wang, H.X. Mu, Y.K. Li, X.N. Li, L.M. Yang, Y.T. Zheng, W.L. Xiao and H.D. Sun, J. Nat. Prod., 76, 250 (2013).

12. H.M. Gao, R.R. Wang, D.Y. Niu, C.Y. Meng, L.M. Yang, Y.T. Zheng, G.Y. Yang, Q.F. Hu, H.D. Sun and W.L. Xiao, J. Nat. Prod., 76, 1052 (2013).

13. T. Mosmann, J. Immunol. Methods, 65, 55 (1983). 